\title{
PARA HABLAR DEL CRIMEN, LA CRIMINOLOGÍA NO BASTA. GABRIEL TARDE, LA RESPONSABILIDAD Y EL SUPERIOR SOCIAL
}

\section{Ezequiel Kostenwein}

Conicet, Instituto de Cultura Jurídica, UNLP, Argentina

Universidad Nacional de La Plata, UNLP- CONICET, Argentina

http://dx.doi.org/10.5209/NOMA.51863

Resumen.- La obra de Gabriel Tarde sigue siendo aún hoy poco explorada, en particular acerca de tos aportes que este autor realizó al campo polivalente de la criminología. En este trabajo se desarrollarán dos tópicos centrales, el de la responsabilidad penal y el del superior social como precursor del delito, a partir de los cuales introduciremos una serie de argumentos que el mismo Tarde postuló al respecto.

Palabras clave.- Tarde, responsabilidad, superior social

To speak of crime, criminology is not enough. Gabriel Tarde, responsibility and social superior

Abstract.- Gabriel Tarde's work still remains unexplored, particularly about his contributions made to the field of criminology. In this paper two central topics are developed, the criminal responsibility and the social superior as a precursor of the crime, from which introduce a series of arguments that Tarde argues about it.

Keywords.- Tarde, responsibility, social superior

Introducción. La responsabilidad: entre la memoria, la deuda y el juicio

Al analizar la imagen del hombre que ofrece Gabriel Tarde en sus escritos surge con frecuencia el problema de la responsabilidad. Y este problema, como eventualmente cualquier otro, tendrá la solución que le corresponda en función de las condiciones de su elaboración (Deleuze y Guattari, 2005). Es por ello que el punto de partida de este trabajo está apoyado en un estatuto muy específico según el cual,

"El hombre sólo recurre al juicio, sólo es juzgable y sólo juzga en tanto en cuanto su existencia está sometida a una deuda infinita: lo infinito de la deuda y la inmortalidad de la existencia remiten uno a otra para construir la doctrina del juicio"l

1 DELEUZE, 1996: 177. 
Siendo esto así, la existencia del hombre ha dejado de ser inocencia cuando pudo volcarse sobre dicha existencia una deuda ${ }^{2}$. A su vez, esto último sólo fue posible gracias a que a ese mismo hombre se le creó una memoria. De esta manera, empezamos a advertir una trinidad no del todo venerable: memoria-deuda-juicio. Más concretamente,

"[...] se trata de dar al hombre una memoria; y el hombre, que se ha constituido por una facultad activa del olvido, por una represión de la memoria biológica, debe hacerse otra memoria, que sea colectiva, una memoria de las palabras y no de las cosas, una memoria de los signos y no de los efectos. Sistema de crueldad, terrible alfabeto, esta organización que traza signos en el mismo cuerpo [...]. La crueldad no tiene nada que ver con una violencia natural o de cualquier tipo que se encargaría de explicar la historia del hombre. La crueldad es el movimiento de la cultura que se opera en los cuerpos y se inscribe sobre ellos, labrándolos. Esto es lo que significa crueldad"3.

En consecuencia, la concepción de responsabilidad a explorar aquí debe evaluarse en relación a la ya mencionada trinidad entre memoria-deuda-juicio. Y si bien los planteos de Tarde en torno al tópico de la responsabilidad están presentes en varios de sus trabajos, él los expone de forma detallada en el primer tomo de su Filosofía penal (1890), y es desde allí que lo abordaremos. Más concretamente, en los tres primeros capítulos trabaja la doctrina del libre albedrío, la scuola positiva y su propio aporte a la cuestión, respectivamente. Y es en especial interesante cómo a partir de concepciones precedentes nuestro autor va apuntalando una propuesta de la que podemos servirnos hoy para profundizar hasta qué punto es justificable el castigo en general, y la forma actual de ejercerlo en particular.

\section{Libertad, deber y derecho}

En las postrimerías del siglo XIX, Tarde comienza a trabajar la viabilidad del libre albedrío a partir de tres elementos: responsabilidad, libertad e identidad personal. Así las cosas, la primera pregunta la formula de la siguiente manera: "¿Con qué condiciones y en qué medida el individuo es responsable de los actos que perjudican a sus conciudadanos?" (1922a [1890]: 18). Esta inquietud, sostiene, se vuelve poco menos que irresoluble si se nos obliga a abonar rápidamente 0 con el ya mencionado libre albedrío o con el determinismo, doctrinas dominantes por aquel entonces. Y sin embargo, doctrinas tan antagónicas como éstas concuerdan en que la responsabilidad moral sólo podrá imputársele a aquél que obre voluntariamente libre. En esto, Tarde comienza a desmarcarse de ambas alternativas:

2 Para una formulación detallada sobre la relación entre existencia e inocencia, véase DELEUZE (2000).

3 DELEUZE y GUATTARI, 1995: 150-1, 196 
"Todo lo que veo claro aquí es que, en la medida en que se aviva nuestra conciencia, nuestra personalidad, no digo nuestra libertad, la preponderancia de las causas interiores sobre las causas exteriores acrece ciertamente, lo que importa mucho en nuestra opinión"4.

Según su propuesta, han existido históricamente dos formas de hacer desaparecer al individuo, o lo que es lo mismo para este caso, su responsabilidad. La primera y más tradicional, fue la absorción por parte de la familia de aquél integrante que había cometido un delito. En la segunda, ha sido su propia raza la que incorporaba al infractor por medio de una solidaridad colectiva ${ }^{5}$. En dichos contextos, separar al individuo sea de la familia, sea de su tribu- para castigarle individualmente equivaldría en la actualidad a "condenar como culpable de un asesinato o un robo a tal circunvolución especial del hemisferio izquierdo o derecho del cerebro de un malhechor, con exclusión de todo el resto del ser" (1922c [1886]: 188). Por otro lado, en casos como estos se está hablando de la identidad de las personas y no de su libertad". Ésta última es "la facultad de la iniciativa primordial, 0 también fundamental. Está comprendida en la necesidad, como la invención lo está en la imitación, como la variación, en general, en la repetición" (1922a [1890]: 30). Y si estamos hablando de libertad, para Tarde no es posible que haya más que dos, o en otros términos, la libertad para él sólo puede poseer dos fundamentos. El de un Dios que concentraría todo eventual albedrío, en tanto creador de lo cognoscible, o el presupuesto según el cual la libertad se halla diseminada entre los incontables componentes del Universo. En concreto, o hay espontaneidad divina o hay espontaneidad elemental y nuestro autor, optando por esta última, se acerca a una suerte de naturalismo: "[...] debe reconocerse en el libre albedrío de la voluntad cierta verdad tal vez; pero no de la que los moralistas dicen tienen necesidad, sino una verdad no limitada al hombre, sino extendida a todos los seres" (Ibíd.: 31).

En suma, tanto lógica como cronológicamente, existe en Tarde una prioridad del deber por sobre el derecho, de la misma manera que ese

\footnotetext{
4 TARDE, 1922a: 20

5 Para indagar una concepción compartida de la responsabilidad, véase MELOSSI (2007).

6 TARDE a menudo utiliza la palabra identidad, la cual es importante entender como semejanza personal de un individuo, que va desde que cometió un hecho hasta cuando es evaluado por él. Para comprender la cosmovisión de nuestro autor, "consideremos las dos fórmulas: sólo lo que se parece difiere, sólo las diferencias se parecen. Se trata de dos lecturas del mundo en la medida en que una nos invita a pensar la diferencia a partir de la similitud o de una identidad previas, en tanto que la otra nos invita por el contrario a pensar la similitud e incluso la identidad como el producto de una disparidad de fondo" (DELEUZE, 2008: 263). La segunda es la utilizada por Tarde.
} 
deber es primero teleológico e individual para transformarse luego en moral y social. De aquí se desprende además que el derecho de castigar es posterior -y derivado- del deber de castigar, por lo cual el problema punitivo nunca se debe plantear en términos jurídicos sino de deseos y creencias": "el interés de nuestro tema se concentra en la cuestión de saber hasta qué punto y en qué condiciones debe ejercitarse ese deber, no en saber cuál es la justicia ideal en relación con el castigo" (Ibíd.: 41). Pero no conforme con esto último, arrastra la cuestión del deber al punto extremo de volver al campo jurídico prescindible en tanto exista una buena convivencia, por lo que "aún en el caso que no existiera en una sociedad ninguna noción de equidad ni de derecho, el sentimiento del deber no dejaría de imponerse a todos cuando existiera un fin común" (Ibíd.: 37).

\section{Nuova Scuola}

El capítulo que Tarde le dedica a la Escuela Positiva es el más sistematizado de toda su Filosofía penal (1890). El apoyo material a esta corriente se lo proveyeron dos disciplinas nuevas por aquel entonces como lo fueron la estadística, de Quetelet y Guerry (Guerry, 1833) por ejemplo, y la antropología, entre quienes se destacaban desde Gall hasta Maudsley, pasando por Broca, Pinell, Esquirol, Morel o Despine (Morel, 1857). En esta Escuela Positiva han surgido una gran variedad de ideas y postulados, si bien para nuestro autor existen tres puntos observables de convergencia: la creencia en la evolución, la negación del libre albedrío y la ausencia de la responsabilidad moral (1922a [1890]: 70). A partir de allí, Tarde considera que el mejor modo de exponer dichos argumentos no es tanto resumir las grandes obras que ha producido la Escuela Positiva sino delinear las respuestas que suministró respecto de problemas relevantes, a saber: ¿̇en qué consiste la responsabilidad descartado el libre albedrío? ¿Qué es el criminal? ¿Qué es el crimen? ¿Cuáles son sus causas? ¿Qué debe ser la pena?

Respecto del tópico de la responsabilidad para la nuova scuola, Tarde no desarrolla en detalle sus fundamentos por lo que sigue un camino hacia la sinuosa prehistoria arribando así al par 'todo ser lucha por su propia existencia" - 'la necesidad de luchar implica la de defenderse contra el agresor'. Esta protección ha asumido a lo largo del tiempo un carácter inmediato, el duelo, y otro mediato, la venganza; esta última es ya un avance respecto del primero. Y la venganza, a su vez, va dejando paulatinamente de ser individual para transformarse en

\footnotetext{
7 Las singularidades en la sociedad se influyen mutuamente, y a distancia, a través de dos elementos: los deseos, también definidos como teleología social, que se observan en las leyes, las costumbres, las instituciones o las industrias; y las creencias, en tanto lógica social, que se encarna en las lenguas, los mitos, las religiones, las ciencias y la filosofía (TARDE, 1922a [1890]; 2006 [1895]).
} 
colectiva. Ocurre que "la evolución de los sentimientos y de las ideas relativas a la pena comprende tres fases: la fase religiosa, la fase ética y la fase social o jurídica" (Ibíd.: 80), y el positivismo nos conduce a la última, entendiendo al derecho como la fuerza específica de los agregados sociales. Si bien hasta aquí no hay algo demasiado innovador por parte de nuestro autor, sí ofrece un planteo novedoso al pensar en los tipos de remedios frente al crimen. Sostiene que estos remedios pueden ser preventivos, reparadores, represivos y eliminadores: "¿Cuál será la regla para ta aplicación de esos diversos remedios a los diferentes casos? [Raffaele] Garófalo responde: el grado de temibilitá del delincuente" (Ibíd.: 81). Tan antigua y tan vigente, la idea de peligrosidad es relativizada por Tarde ya que según sus propias palabras, frente a la abstracción que supondría el diagnóstico determinista de Garófalo, considera que no podemos prescindir ni del acto ni del hombre que lo ha realizado para tomar decisiones por lo cual las predicciones, inclusos las criminológicas, tienen que seguir siendo sólo eso, predicciones, cuya utilización debe ser siempre restringida.

En torno al criminal, alude a la contribución que significó precisar por parte de la nuova scuola la idea de que un grupo de aquellos se muestre como incorregible, hecho que no era tenido en cuenta por los clásicos. No obstante, la gran distinción se halla entre los delincuentes de hábito y de ocasión: "La insensibilidad moral explica con preferencia el delito de hábito, y la imprevisión el delito de ocasión" (Ibíd.: 83). Dicho esto, Tarde indaga en la idea lombrosiana del criminal nato, considerándola inverosímil puesto que, nos dice, si se toma en cuenta la clasificación hecha por Ferri ${ }^{8}$, o esa categoría es pura artificialidad, o entra en la de criminal loco o en la de criminal de hábito, por lo tanto,

"no queda más que el delincuente por hábito y el delincuente ocasional, el uno enfrente del otro; pero, ¿̇cómo distinguirles con precisión absoluta? No siempre la ocasión hace al ladrón y al asesino ¿Cuál es la costumbre que no tiene por principio un accidente y cuál es el acto accidental que no tiende a reproducirse, a consolidarse en hábito?"9.

Éstos son los dilemas que deben elucidarse para el magistrado francés. Por ello al criminal, a aquel que lo es por hábito, hay que estudiarlo

"bajo su aspecto sociológico, es decir, como miembro de una sociedad especial que tiene sus costumbres [...] ¿ Cómo se llega a ser camorrista? Como se llega a ser miembro de... una logia masónica, de una

8 La recordada tipificación de Enrico FERRI constaba de delincuentes natos, locos, habituales, pasionales y ocasionales (Ferri, 1907, 1907b).

9 TARDE, 1922a: 95 
compañía teatral, por elección, luego de una prueba regular seguido un aprendizaje más o menos largo [...]"10.

Indagar al criminal así supone, primordialmente, historizar aquello que lo define como tal, relativizando valores humanos ya que "puesto en su lugar, hubiera sido un hombre honrado, quizá un héroe" (Ibíd.: 169).

Al hablar del crimen, Tarde comienza exigiendo dos cosas: en primer lugar, que se puntualice su definición, la cual ha sido relegada y resulta prioritario alcanzarla (Ibíd.: 37). Segundo, que se lo distinga del criminal, como se diferencia el acto de la potencialidad.

Al referirse a las causas del delito, si bien éstas son múltiples, nuestro autor elije destacar las siguientes: "no puede desconocerse la parte que toma la sóciedad en la producción del delito, ya proporcionando las ocasiones, ya atribuyendo, más o menos arbitrariamente, a ciertas acciones, carácter criminal"11 (1922a [1890]: 95). Es decir, que en los orígenes del crimen Tarde ve algo similar a lo que varias décadas después denunciaría la teoría de la reacción social: que el delito es resultado de una etiqueta exitosamente colocada. Por el contrario, para Garófalo (1912) existen sentimientos universales y persistentes en todo hombre decente que viene al mundo, pudiéndose sintetizar ello en un mínimum de piedad y un mínimum de probidad. Nuestro autor, crítico de esta elaboración, expone sus motivos:

"Lo que aquí hay de extraño es el ver a un evolucionista hacer este desesperado esfuerzo para afirmarse en un punto fijo en el mar sin fondo de los fenómenos, y arrojar el ancla precisamente en lo que hay de más fluido en el mundo y más inaccesible: la sensibilidad"12.

Quizá esta cita resuma aquello a lo que cualquier criminólogo debería acercarse a su problema de investigación. Dicho con otras palabras, el verdadero sustrato de la cuestión criminal, o la auténtica introducción a la criminología no son las escuelas, sea Clásica, sea Positiva, ni una teoría del Estado y sus avatares políticos. Lo primero que debe saber quien se inicia en esta actividad es la variación absoluta que ofrece el material sobre el cual va a trabajar de allí en adelante: este material es el mar sin fondo de la sensibilidad humana. Sintetizando, zqué debemos, desde su perspectiva, reputar como crimen?

"[...] un acto sentido por el grupo social ambiente como un ataque y un problema..., una voluntad [que] se levanta contra otra voluntad juzgada superior [presentando] en diferentes grados, ese doble carácter de ser un peligro social y una ofensa social -un peligro social a prevenir, o una ofensa social a corregir"13.

\footnotetext{
10 TARDE, 2011 [1885]: 175-176

11 La cursiva es nuestra.

12 TARDE, 1922a: 98

13 TARDE, 2011 [1898]: 45-52
} 
Finalmente, los planteos del positivismo refieren a los remedios contra el delito, entre los cuales la fiereza del castigo siempre posee un papel harto insignificante. Ahora bien, está claro que la verdadera solución respecto del crimen es atacar sus causas, y sobre las únicas que nos es dable intervenir, indica Tarde, es sobre las sociales, y sólo en algunas de ellas. Para él, estos lineamientos carecieron del desarrollo suficiente por parte de la scuola, incluso en Ferri quien no presentó más que un bosquejo sin relieve al respecto (lbíd.: 106). Y contradiciendo a quienes sólo ven en Tarde a un magistrado de tinte conservador, nuestro autor afirma que "conviene en materia criminal sustituir el punto de vista estrictamente jurídico por el punto de vista sociológico más vasto y elevado" (Ibíd:: 108). La convicción tan precursora, a fines del siglo XIX, de que las ciencias sociales deban preponderar sobre el espectro del derecho es algo que aún hoy atemoriza a los penalistas. Por supuesto que no es la simple afirmación aquello que transforma a Tarde en un vanguardista, sino la manera en que elige plantear los problemas, que como ya hemos dicho, es donde se alojan las soluciones. Más en concreto, "es la resolubilidad la que debe depender de una característica interna: debe hallarse determinada por las condiciones del problema, al mismo tiempo que las soluciones reales, engendradas por y en el problema" (Deleuze, 2002: 247).

Consideramos que, aún en los casos donde Tarde se muestra reaccionario a nivel molar -o de las grandes representaciones-, sus planteos favorecen -a nivel molecular o de la política cotidiana- fisuras en las cuales puede brotar cierta efervescencia en el pensamiento sobre la cuestión criminal (Guattari y Rolnik, 2006).

Hasta aquí, presentamos los dos polos de la responsabilidad -libre albedrío y determinismo-, por lo que nos resta mostrar lo que el mismo Tarde añadió al problema, y las derivaciones refractarias que ofrece al sendero punitivo.

\section{Sin similitud social, no hay crimen}

La pregunta ya realizada acerca de las condiciones en que es exigible al hombre el pago de una deuda, Tarde la desplaza de la libertad a la causalidad y a la identidad, entre otras cosas porque considera más factible determinar en un momento dado si una persona es la misma que fue en un tiempo anterior que poder definir hasta qué punto actúa libre de todo condicionamiento. Dicho con otras palabras, la identidad es una fuerza evidente y la libertad una fuerza latente: "¿Es esto decir que sólo basta la idea de identidad individual? No; es preciso unirle a la de similitud social. [...] solamente combinando esas dos nociones se encuentra la solución plausible del problema" (1922a [1890]: 119).

El fundamento de la identidad individual lo encontramos en la memoria y el hábito, de la misma manera que el de la similitud colectiva estará 
en la tradición y la costumbre (Ibíd.: 126), con un diagnóstico de nuestro autor que podría recordarnos a esa imagen durkheimiana de las sociedades primitivas definidas por una solidaridad mecánica:

"Por consecuencia, un estado social excelente verdaderamente estable, se compone en todo lugar y en todo tiempo de fuertes convicciones semejantes y de débiles orgullos diferentes, de grandes necesidades de una acción común y de pequeñas necesidades de goce privados"14.

Tomando en cuenta to dicho por Tarde, es posible reconsiderar lo que en la actualidad Roberto Gargarella define como alienación legal (2005: 205), y al modo en que esta vinculación puede redundar en la deslegitimación del ejercicio del poder punitivo en las condiciones vigentes. En este sentido, debemos tener en claro que la similitud social, esto es, la similitud entre los individuos hacia dentro de su comunidad, nada tiene que ver con los rasgos del rostro o con su capacidad craneana, sino con todas aquellas inclinaciones de las personas que provengan del ejemplo ambiente, la educación común y las costumbres reinantes. Allí, y sólo allí, estamos en condiciones de poder juzgar a un individuo en tanto ser social:

"Es condición indispensable, para que se despierte el sentimiento de la responsabilidad moral y penal, que el autor y la víctima del hecho sean más o menos compatriotas sociales, que presenten número suficiente de semejanzas de origen social, esto es, imitativo" 15 .

Lo que permite confirmar la importancia de la categoría de similitud social es que sin ella es arriesgado -y sumamente indecoroso- pretender inculpar a alguien. El sentimiento por el derecho, de considerarlo digno de respeto, debe ser fruto y no causa de esta similitud, o lo que es lo mismo, el derecho es predominantemente un producto de las relaciones sociales, y en escasa medida creadora de ellas:

"el malhechor será plenamente responsable en el sentido de que se trata, siempre que se vea obligado en el fondo de su corazón a censurar el acto que ha cometido en virtud de la concepción del bien y del mal que recibió de su medio honrado"16.

Es posible que tas afirmaciones de Tarde generen de parte de los criminólogos tradicionales una impugnación virulenta: "más o menos compatriotas", "censurar un acto en el fondo de su corazón", resultan poco familiares a la nomenclatura de los doctrinarios del Estado. Pero también es cierto que la sensatez de sus afirmaciones pueden evaluarse como el encuentro entre la pre-criminología y la no-criminología, la boda de dos reinos que hace posible un resbalón en la rigidez de las

14 TARDE, 1922a: 122

15 TARDE, 1922a [1890]: 119. La cursiva es nuestra.

16 TARDE, 1922a [1890]: 142 
ideas consolidadas. En definitiva, este es el efecto que creemos que Tarde ha provocado en la criminología, insuflando un nuevo sentido para la misma:

"no es tan verdad como se ha dicho que la lucha por la vida, que la hostilidad radical de los seres y de sus elementos, sea el primero y fundamental principio del Universo. No es [...] más que el segundo. El primero es, como se ha hecho observar, la asociación para la vida, la solidaridad interna de esos seres mismos [...]"17.

Nos encontramos en presencia de un Tarde que se acerca a Spinoza con la misma determinación que se aleja de Hobbes (Virno, 2003), un Tarde para quien los agregados sociales son el punto de encuentro de afectos que deben potenciarse, para quien la libertad de un individuo no acaba cuando comienza la de los otros, sino que se aumenta en sus intersecciones.

Lo que podríamos preguntarnos ahora es, entonces, si la situación actual del derecho asegura, o al menos refleja, esa similitud social necesaria -según Tarde- para poder hacer responsables a los agentes de los hechos que caracterizan comúnmente el horizonte construido por el sistema penal.

Sin temor a equivocarnos, podríamos apresurarnos y decir que el derecho no garantiza esa semejanza, lo cual tampoco aclararía demasiado la cuestión. Aceptando que el derecho no opera como nexo entre los individuos, el interrogante que surge es żpor qué? Una respuesta posible es que diversos grupos en la sociedad sienten una enorme extrañeza respecto del mismo, fenómeno que ya señalamos como alienación legal, es decir, "una situación en donde el derecho no representa una expresión más o menos fiel de nuestra voluntad como comunidad sino que se presenta como un conjunto de normas ajenas a nuestros designios y control [...]" (Gargarella, 2005: 205-206), impidiéndonos participar tanto en la creación como en la modificación del mismo.

Si bien no pretendemos reiterar la manida crítica al desigual acceso a la justicia y el carácter genéticamente selectivo de la persecúción penal, sí deseamos plantear lo siguiente: la policía, el poder judicial y el servicio penitenciario, trabajan principalmente con determinado estrato social, que resulta ser el más olvidado respecto a sus necesidades, y el más estereotipado en tanto portador de peligros para la comunidad ${ }^{18}$. Y es

\footnotetext{
17 TARDE, 1922a [1890]: 137

18 Sobre el modo en que el Estado posterga a grupos enteros a la hora de otorgarles derechos, y que sólo recurre a ellos cuando considera necesario encarcelarlos, BARATTA afirma: "Después que se ha olvidado a una serie de sujetos vulnerables provenientes de grupos marginales o "peligrosos" cuando estaba en juego la seguridad de sus derechos, la política criminal los reencuentra como objetos de política social. Objetos, pero no sujetos, porque también esta vez la finalidad (subjetiva) de los
} 
por esto que surge el dilema sobre el deber de castigar a personas que no son tenidas en cuenta en la formulación de los postulados jurídicos, sumado al hecho de que ni siquiera logran comprender el críptico lenguaje de los juristas: "Para que haya vínculo de derecho, por el mero efecto de una promesa, [...] es preciso que haya sido aceptado por aquél o aquellos a los que se dirige y que se supone existe una relación personal entre ellos" (Tarde, 1986 [1901]: 70). Por lo tanto, ¿̇es legítimo ese deber de castigar a quienes no han recibido del derecho más que estigmatización? ¿̇Es un deber respetar el conjunto de las normas jurídicas que sólo los muestran como sujetos pasivos del derecho? Según Tarde, si no hay deber no hay derecho, abriendo la posibilidad a planteos claramente radicales. En este sentido, si hay individuos en la sociedad a los que se mantiene apartados permanentemente de la intervención en la vida política, y junto con esto se hallan privados de los recursos elementales para su desarrollo, suponer que ellos, en tanto ciudadanos, se encuentran obligados a respetar las leyes y que deben comprometerse con la comunidad, se vuelve un reclamo cínico (Duff, 2001).

De lo que estamos hablando, entonces, es de intentar reformular el espinoso tema de la justificación del castigo, y no precisamente aludiendo a aspectos técnicos o jurídicos, sino desde un devenir crítico respecto a la coagulación de determinados aparatos discursivos que surgen de una relación baja y mezquina entre el saber y el poder punitivos. Evaluar, entonces, si no

"hemos olvidado rápidamente los viejos poderes que ya no se ejercen, los viejos saberes que ya no son útiles, pero, en materia moral, no cesamos de saturarnos de viejas creencias en las que ya ni siquiera creemos, de producirnos como sujeto a partir de viejos modos que no corresponden a nuestros problemas"19.

En definitiva, si el derecho toma a grupos enteros como meros objetos -y sencillamente resulta difícil afirmar otra cosa- es motivo suficiente para resistirlo, para impugnarlo, para erosionarlo. Si como afirma Tárde, el castigo es una cuestión de deber antes que una cuestión de derecho, para acabar con el castigo es preciso un nuevo reparto de las creencias y los deseos sociales, de nuestras propias secreciones, y no una resonante modificación legislativa.

\section{Génesis del crimen: el superior social}

Para Gabriel Tarde pensar la responsabilidad penal de los individuos es el puntapié para analizar más rigurosamente el problema del delito. Así

programas de acción no es la seguridad de sus derechos, sino la seguridad de sus potenciales víctimas" (BARATTA, 2004: 158).

19 DELEUZE, 2008b: 140 
las cosas, nuestro autor insiste en lo siguiente: debemos ser cautelosos a la hora de elogiar todo aquello que ofrezca signo de mayor evolución o adelanto social. La nobleza y el pueblo, la ciudad y el campo, entre otros, son los opuestos a partir de los cuales Tarde desacraliza la cuestión criminal, transformándose de ese modo en un activo precursor de la Escuela de Chicago, y de Edwin Sutherland en particular. En este sentido, el delito -como cualquier otra destreza- se imita o se aprende -o se aprende imitando-, y en la mayoría de los casos se dirige desde arriba hacia abajo de la escala social, desde los centros urbanos a las huertas más elementales. El delito se aprende

"en contacto con otras personas mediante un proceso de comunicación, sobre todo en el interior de un grupo restringido de relaciones personales. Cuando se ha adquirido la formación criminal ésta comprende: a) la enseñanza de técnicas para cometer infracciones que son unas veces muy complejas y otras veces muy simples, b) la orientación de móviles, de tendencias impulsivas, de razonamiento y de actitudes. La orientación de los móviles y de las tendencias impulsivas está en función de la interpretación favorable o desfavorable de las disposiciones legales. Un individuo se convierte en delincuente cuando las interpretaciones desfavorables relativas a la ley prevalecen sobre las interpretaciones favorables. Las asociaciones diferenciales pueden variar en lo relativo a la frecuencia, la duración, la anterioridad y la intensidad. La formación criminal mediante la asociación con modelos criminales o anti-criminales pone en juego los mismos mecanismos que los que se ven implicados en cualquier otra formación. Mientras que el comportamiento criminal es la manifestación de un conjunto de necesidades y de valores, no se explica por esas necesidades y esos valores puesto que el comportamiento no criminal es la expresión de las mismas necesidades y de los mismos valores"20.

Esto último representa uno de los planteos más incisivos de la criminología de todo el siglo XX. Se trata de cómo Sutherland explica en 1939 su teoría acerca de la asociación diferencial, la cual ha servido para conceptualizar lo que por aquel tiempo resultaba invisible a los estudios criminológicos: el delito de cuello blanco.

Ahora bien, Tarde considera que cualquier evento, como por ejemplo lo es el delito, debe evaluarse bajo tres aspectos: el de la repetición -o imitación-, el de la oposición y el de la adaptación -o invención-. La ciencia, entonces, precisa indagar respecto de los distintos fenómenos no tanto sus causas como sí estas tres leyes que aún siendo solidarias entre ellas, en la misma medida difieren:

"de estas tres llaves, la primera y la tercera son mucho más importantes que la segunda. La primera y la segunda constituyen lo que podríamos llamar una ganzúa poderosa; la tercera, más delicada, da acceso a los

20 SUTHERLAND, 1999: 35-36 
más ocultos y más preciados tesoros; la segunda, intermediaria y subordinada, nos revela los choques y las luchas de una utilidad pasajera, especie de término medio destinado a desvanecerse poco a poco, aunque nunca por completo, y a no desaparecer sino parcialmente y después de numerosas transformaciones y atenuaciones"21.

Hay trabajos que siguen con pericia los postulados tardeanos respecto de la ciencia, y en este sentido presentan al delito en tanto acontecimiento inventivo, luego como propagación imitativa y al fin, considerándolo fenómeno de oposición (et al., Tonkonoff, 2008; 2011). Si bien es legítimo este itinerario, entendemos que existen otras posibilidades como por ejemplo la tomar el pensamiento de Tarde como un acto peligroso, en su variación continua, dejando de lado cualquier intención pedagógica que privilegie la progresividad de una serie de ideas. En palabras de Deleuze, "La lógica de un pensamiento es el conjunto de las crisis por las que atraviesa, se parece más a una cordillera volcánica que a un sistema tranquilo y aproximadamente equilibrado" (1999: 137). Por lo tanto, quisiéramos seguir una línea que se afinque principalmente en el fenómeno delictivo caracterizado por el modelo del superior social (Tarde, 1922b [1890]: 49), que lo aplicaremos a partir de los dos binomios nobleza-pueblo y ciudad-campo:

"[...] el crimen es a nuestros ojos un hecho social especial; pero, después de todo, un hecho social como otro cualquiera. Es una rama parásita del árbol nacional; pero se nutre de la savia común y está sometida a las leyes comunes. Hemos visto que, considerada aparte, crece, conformándose a la regla de la imitación, de alto a bajo, como todas las demás ramas fructíferas y útiles del mismo tronco"22.

Dicho esto, el mismo Tarde se encarga de, no obstante confirmar la semejanza entre el crimen y los otros hechos sociales, evidenciar sus diferencias. De allí se deriva que el crimen es un fenómeno simultáneamente poseedor de carácter social y anti-social, que trabaja como cualquier otro componente en la vida de la comunidad, aunque lo haga además autodestructivamente.

Una vez formulado lo anterior, nuestro autor sugiere un proverbio inquietante: "Un crimen útil procura el grado de oficial" (1922b [1890]: 178). De este modo intenta describir el paso del bandolerismo al militarismo, mediante el cual no pocos facinerosos recalcitrantes saltan a engrosar las filas del ejército más disciplinado sin que moralidades o sensibilidades impidan dicho traspaso. Esta distinta vara para medir licitudes e ilicitudes no es asunto que haya terminado el la época de Tarde. Por el contrario, en la criminología contemporánea se asevera que la

21 TARDE, 1983 [1897]: 9

22 TARDE: 98; 1922C [1886]: 109-114 
"distribución asimétrica de la libertad hace que algunos conviertan los comportamientos de otros en medios para sus propios objetivos. Esto puede ser realizado a través de medios legítimos o coercitivos, lo que garantiza a aquellos beneficiados con mayores recursos la prerrogativa de establecer qué medios y qué fines van a ser considerados aceptables"23.

En cierta medida, lo que este planteo nos facilita advertir es aquello que Durkheim (2004) se rehusaba aceptar, y es que el sustento del derecho penal no es el conjunto de valores y creencias compartidas por los ciudadanos medios debido al carácter sagrado que ostentan. En primer lugar, afirma Tarde, debería "saber[se] cómo es que esta conciencia colectiva llega a ser tal, es decir cómo, en un momento dado, se encuentra presente en todos los espíritus a la vez" (2011 [1898]: 44). Por lo tanto, el sustrato del fenómeno jurídico-punitivo parece ser la arbitrariedad, aunque logre ser naturalizada. Incluso más allá de que sus efectos del castigo sean circunstancialmente beneficiosos para la sociedad, esto último no le quitaría al derecho su génesis tiránica. Algo cercano a lo que sostuviera Howard Becker, para quien es muy importante

"enfocar la atención sobre la manera en que el etiquetado coloca al actor en una situación que le dificulta llevar una rutina diaria normal, y por lo tanto lo conduce a realizar acciones 'anormales' (como cuando los antecedentes penales hacen que una persona tenga problemas para ganarse la vida en una ocupación convencional y la predisponen a volcarse a actividades ilegales)" 24.

Al no estar imparcialmente distribuido el poder de los distintos grupos sociales para definir qué será desviado y qué no, cuál delito será oficial y cuál no, tanto Tarde como Becker dejan abierta una serie de interrogantes primordiales para el devenir crítico de la criminología: ¿quién establece las normas y por qué razones? ¿Cuándo y cómo se aplican? ¿Qué efectos produce esto en las personas etiquetadas? Indagar sobre esto supone un enorme impacto respecto de la cuestión criminal, dado que "las reglas sociales [incluyendo las jurídicas] son la creación de grupos sociales específicos. Las sociedades modernas no son organizaciones simples en las que hay consenso acerca de cuáles son las reglas y cómo deben ser aplicadas en cada caso específico" (Ibíd.: 34).

Con esto no pretendemos ubicar a Tarde en el origen de la teoría de la asociación diferencial ni tampoco del labelling approach. En todo caso, exaltamos el encuentro para hacer hablar a los autores que tanto

23 RUGGIERO, 2005: 217

24 BECKER, 2009: 197 
admiramos, intuyendo que ellos están siguiendo un mismo camino, que están 'en el mismo barco' 25.

\section{De la nobleza al pueblo}

El pueblo se embriaga, fuma, se vuelve irreligioso, se inclina por la vagancia o la caza furtiva. Frente a esta problemática, Tarde considera que existen demostraciones convincentes para afirmar que "los vicios y crímenes localizados hoy en las últimas filas del pueblo han caído allí desde lo alto" (1922b [1890]: 53), y que las conductas mencionadas fueron, en tiempos anteriores, patrimonio de las clases superiores, es decir, de la nobleza. Es por eso que nuestro autor asevera que el poder de matar ha sido previo al derecho a matar, y que en siglos anteriores resultaba el carácter distintivo de las clases elevadas: "La evolución del asesinato político es instructiva. Hubo un tiempo en que los reyes [...] asesinaban por sí mismos [...] a sus próximos parientes" (Ibíd.: 56). Es la crueldad de los antiguos justicieros proveniente de las alturas la que sirvió de ejemplo a las almas plebeyas y feroces. Lo mismo con la falsificación de la moneda o con el robo. En definitiva, debemos recordar que "hubo una época en que los hombres de Estado no se avergonzaban de cometer las matanzas y exacciones que reprimen en nuestros días" (lbíd.: 61), y que cualquier individuo cuya criminal industria lograse prosperar socialmente podría, eventualmente, hacerse proclamar rey.

En consecuencia, Tarde no sólo encuentra en el fenómeno criminal factores sociales que lo explican, sino también a personas que aprovechando su situación privilegiada -incluso su impunidad-cometen actos que sólo tiempo después, y en tanto les resulten inoportunos o riesgosos, serán definidos como delictivos: "El carácter propio que revisten tanto las virtudes como los vicios de un pueblo, proviene de sus antiguos jefes" (lbíd.: 62).

Es cierto que nuestro autor realiza, para explicar el hecho social de la imitación, una diferenciación entre las emulaciones que ocurren espontáneamente y aquellas que sobrevienen por la coacción militar y política. Éstas últimas, según Tarde, no progresan jamás, siendo las imitaciones espontáneas provenientes del superior social las que despiertan contagio o sugestión sostenida, las que se logran imponer: "el más rico en ideas civilizadoras, aún cuando sea diferente del superior político, y opuesto al mismo, [es] el que acaba por triunfar [...]" (lbíd.: 49).

25 Según la expresión de David HUME: "Cuando dos hombres impulsan un bote a fuerza de remos lo hacen en virtud de un acuerdo o convención, a pesar de que nunca se hayan prometido nada mutuamente" (1984: 715). 
En la misma línea, Tarde asevera en el segundo tomo de su Filosofía penal que las jerarquías sociales poseen la gran utilidad de beneficiar la difusión de los ejemplos: "una aristocracia es un depósito de agua necesario para la caída de la imitación en cascadas sucesivas, sucesivamente puesta en libertad" (Ibíd.: 51). Notamos aquí cierta afinidad con algunos planteos realizados lvego por Norbert Elías en El proceso de la civilización (1939) respecto de la imitación del superior social. Está claro que sus intereses divergen sensiblemente de los de Tarde, lo que lo lleva a plantear la suavización de los comportamientos en diversas esferas (higiene, alimentación, vestimenta, intimidad, etc.), más que ceñirse al impacto sobre la criminalidad. Para Elías,

"Hay una multiplicidad de ejemplos que demuestran que, en esa época, penetraron en las clases medias superiores los usos, las formas de comportamiento y las modas de la corte; al imitarlos, las clases medias, además, los cambiaron, como era de esperar dadas las diferencias existentes en lo relativo a las relaciones sociales. Con esto, además, también pierden, hasta cierto punto, su carácter de medio de diferenciación de la clase alta. Se desvalorizan parcialmente. Esto, a su vez, impulsa en la clase alta un refinamiento y una elaboración posteriores de los comportamientos" 26 .

Simplificando, el argumento eliasiano supone que las imitaciones tienen un papel crucial para entender cómo es posible el proceso civilizatorio y la "dulcificación" de muchos aspectos de la vida social. El esquema sería el siguiente: desarrollo de las costumbres con expansión hacia abajo, leve deformación social, devaluación como rasgo distintivo. Ocurre que, justamente, esas emulaciones no siempre logran ajustarse con precisión y eso

"lo encontramos en los círculos pequeño-burgueses de la sociedad occidental como un "barniz cultural», es decir, como el anhelo de ser algo que no se es, con la correspondiente inseguridad del comportamiento y del gusto, con la "cursilería» no solamente en muebles y atavíos, sino también en el espíritu; todo esto pone de manifiesto una situación social que incita a la imitación de los modelos de otro grupo social de posición superior, pero, al no conseguirse, la asimilación sigue siendo reconocible como un intento de imitación de modelos extraños" 27 .

Esta seducción aristocrática de la que es presa, en lo fundamental, la clase media en ascenso provoca su propio deterioro como consecuencia de los sentimientos de vergüenza y supeditación que esa misma distancia social, por lo común insuperable, le provoca.

En suma, la imitación es el hecho social fundamental en Tarde, y resulta uno muy importante en Elías. Los cambios en el modo de realizar las

26 ELÍAS, 1993: 145

27 ELÍAS, 1993: 515 
necesidades fisiológicas o los comportamientos en el dormitorio, el homicidio o el robo, parecen tener mucho que ver con la sugestión que los superiores sociales han despertado. En todo caso, civilización y violencia a veces se asemejan demasiado (Elías 1994).

\section{La ciudad y el campo}

Área moderna y deslumbrante, la ciudad es para Tarde un foco de circulación, no sólo de concepciones políticas o literarias, de modas o argots, sino también de propuestas delictivas y criminales, el epicentro donde todo tipo de conductas indeseables se encuentran exhibidas y al alcance de sus habitantes. Esta influencia, que según nuestro autor está en condiciones de provocar una fascinación incontrolable sobre los campesinos sediciosos, puede ser directa -como en el caso de la utilización del vitriolo que emplean las mujeres para arrojarlo sobre el rostro de sus amantes- o indirecta -por ejemplo las noblezas antiguas que al propagar sus placeres y sus vicios atraen a las poblaciones rurales a los centros urbanos, haciendo posible su imitación (1922b [1890]: 65)-. Así entendido, el fenómeno del delito es un flujo social que consigue desplazarse desde la metrópolis hasta las zonas menos urbanizadas, 0 atraer hacia las ciudades al conjunto de campesinos que se encuentren hipnotizados por las convenciones aristocráticas:

"Es preciso guardarse de confundir los delitos de las regiones montañosas, amparadas por las costumbres antiguas, con los de las regiones urbanas [...], la imitación de los ascendientes rurales ha sido reemplazada por la imitación de los extraños de la ciudad o de los vecinos urbanizados"28.

Entonces, estudiar la criminalidad de las grandes capitales es de vital importancia por el doble foco-directo e indirecto- que supone para el fenómeno del delito. Estas amplias aglomeraciones son las que sin duda han provocado, al menos para Tarde, un incremento frenético en las cifras de las transgresiones. Ahora bien, si la acción extendida de las metrópolis sobre la criminalidad es unívoca, surgiría a raíz de eso una aparente incongruencia: ¿̇cómo ensamblar la consternación que la civilización ha provocado a partir de la creación de las grandes ciudades respecto de las corrientes delictivas con el mejoramiento moral que la misma civilización supuso en otras esferas de la vida social? Tarde nos vuelve a ilustrar acerca de que en el modo de plantear los problemas, ya está engendrada la solución:

"La contradicción se reduce, según creo, a un equívoco [...]. El problema, tan agitado, de las relaciones que existen entre las corrientes de la civilización y el movimiento o el cambio de la criminalidad exige se precise para ser resuelto. Lo expresaremos de otro modo. Siendo

28 TARDE, 1922b: 75 
siempre la criminalidad, en su forma característica y su realización en hechos, un fenómeno de propagación imitativa, se trata de saber si los demás fenómenos múltiples de propagación imitativa, que se llama en bloque la civilización [...], favorecen o coartan el progreso de la propagación criminal"29.

La criminalidad, por lo tanto, no puede explicarse a partir de sí misma, ni de los individuos aislados, ni del conjunto de creencias y valores comunes al término medio de la sociedad. El problema de la criminalidad es relacional, y lo evaluaremos más ajustadamente si se lo vincula con el resto de los fenómenos sociales a partir de los cuales dicha criminalidad tiene sentido. En términos generales, el proceso de civilización mencionado, ¿̇beneficia o detiene el avance del delito? Todos esos comportamientos que se aprenden e imitan cotidianamente, y que conforman dicho proceso, ¿dan lugar a que aumenten determinados ilícitos y otros disminuyan? Y en todo caso, ¿̇a qué motivos responde? En definitiva, lo que la criminología 30 debe buscar es justipreciar el valor del crimen y del castigo en función del resto de las cosas sociales que progresan según la civilidad lo indica: "Las transformaciones del derecho criminal [...] se moldean sobre las transformaciones del delito, las cuales, también ellas, se rigen por las del valor" (2011 [1893]: 63). Sólo en interacción con el conjunto de fenómenos normativos serán comprensibles los dos elementos mencionados.

Como consecuencia del planteo previo, se podrá objetar falta de originalidad por parte de Tarde puesto que en la actualidad, ¿̇qué criminólogo está en condiciones de rechazar de plano la importancia de examinar la relación entre lo permitido y lo prohibido para comprender, al menos en parte, la cuestión social del delito? No obstante, es posible alegar que cuando Tarde lo proponía, la perspectiva sociológica de la criminología no resultaba hegemónica, más bien lo contrario. Pero aún así, esto último no lo distinguiría demasiado de Durkheim (1982), dado que este último aseveraba al respecto prácticamente lo mismo. De modo tal que ofrecemos un segundo argumento: como dijimos hace un instante, para Tarde lo primordial es diagnosticar el valor del crimen y del castigo, y esto lo obtiene -a diferencia del autor de Las reglas del método sociológicodesmenuzando el entrelazamiento de tres fuerzas que surcan el campo social. La tradición -en tanto extracto y acumulación de la opinión y los prejuicios de los muertos que gravitan sobre los vivos-, la razón -que es producto de los juicios de quienes se aíslan de la corriente popular para lvego ayudarle a encauzarse- y finalmente, la opinión -como

29 TARDE, 1922b: 97

30 TARDE era claro respecto a lo siguiente: "La criminología, repitámoslo una vez más, es sólo un caso de la sociología tal como nosotros la entendemos" (1922b [1890]: 128). 
agrupación momentánea de juicios que responden a cuestiones actuales y se encuentran depositadas en varias personas-. Según Tarde,

"todo iría de la mejor manera si la opinión se limitase a vulgarizar la razón para consagrarla y convertirla en tradición, porque, de esta manera, la razón de hoy se convertirá en la opinión de mañana, y asimismo, en la tradición de pasado mañana. Pero, en lugar de servir de lazo de unión [...] la opinión prefiere tomar partido [...] y, tan pronto, embriagándose de las nuevas doctrinas a la moda trastorna las ideas o las instituciones consuetudinarias antes de poder reemplazarlas [...]"31.

Basta recordar la célebre crítica que se le ha hecho a Durkheim respecto de la falta de historización en su explicación acerca de la función del delito y el papel del castigo en la sociedad (et al., Garland, 1990) para valorar el aporte de Gabriel Tarde, quien tiempo antes supo ofrecer herramientas para enmarcar esta problemática, sugiriendo que lo que el crimen sea, lo vislumbraremos en el intersticio de los tres vectores sociales -la tradición, la razón y la opinión- que pujan entre ellos siempre en forma voluble y desigual. En sus propias palabras, "[...] la criminalidad tiene por causa principal, quizá por única, las contradicciones sociales que son las crisis crónicas de las sociedades [...]" (2011: 79).

\section{Conclusión}

Parte del legado de Gabriel Tarde que intentamos recuperar con este trabajo puede resumirse a partir de dos de sus categorías que sin dudas podemos calificar de contraintuitivas para el momento en el cual se plantearon: la de similitud social y la de superior social. Sobre la primera, que la responsabilidad penal sólo puede exigírsele a quienes no hayan sido sistemáticamente excluidos de sus derechos puesto que la identidad o similitud social nos es concedida a partir de un mínimo común de deseos, de creencias, de tradición, de razón, de opinión. Sin esto, que en definitiva debería ser el sustrato elemental de toda justicia social, ninguna persona podría ser considerada socialmente dueña de sus actos. Sobre la segunda, que los orígenes de algunos comportamientos delictivos están en las nobles alturas criminales, lo cual les ha asegurado históricamente tanto la legitimidad como la impunidad, invisibilizando no sólo una batería de transgresiones sino también sus nocivas consecuencias sociales.

31 TARDE, 1986 [1901]: 80-81 


\section{Bibliografía}

BARATTA, A. (2004). Criminología y sistema penal, Bs. As.: B de F

BECKER, H. (2009). Outsiders, Bs. As.: Siglo XXI

DELEUZE, G. (1996). Crítica y clínica, Barcelona: Anagrama

DELEUZE, G. (1999). Conversaciones, Valencia: Pre-Textos

DELEUZE, G. (2000). Nietzsche y la filosofía, Barcelona: Anagrama

DELEUZE, G. (2002). Diferencia y repetición, Bs. As.: Amorrortu

DELEUZE, G. (2008). Lógica del sentido, Bs. As.: Paidós

DELEUZE, G. (2008b). Foucault, Bs. As.: Paidós

DELEUZE, G. y GUATTARI, F. (1995). Antiedipo, Barcelona: Paidós

DELEUZE, G. y GUATTARI, F. (2005). ¿Qué es la filosofía?, Barcelona: Anagrama

DUFF, A. (2001). Punishment, Communication, and Community, Oxford: Oxford University Press.

DURKHEIM, E. (1982). Las reglas del método sociológico, Madrid: Hyspamerica

DURKHEIM, E. (2004). La división del trabajo social, Bs. As.: Libertador

ELÍAS, N. (1993). El proceso de civilización, México: FCE

ELÍAS, N. (1994). Civilización y violencia, REIS, Madrid, N 65, p. 141-151

FERRI, E. (1907). Sociología Criminal Tomo I, Madrid: Editorial de Góngora ELÍAS, E. (1907b). Sociología Criminal Tomo II, Madrid: Editorial de Góngora

GARGARELLA, R. (2005). El derecho a la protesta, Bs. As.: Ad-Hoc

GARLAND, D. (1990). Punishment and modern society, Chicago, University of Chicago Press

GARÓFALO, R. (1912). La criminología, Madrid: Daniel Jorro

GUATTARI, F. Y ROLNIK, S. (2006). Micropolítica. Cartografías del deseo, Madrid: Traficantes de sueño

GUERRY, A. M. (1833), Essai sur la Statistique Morale de la France avec Cartes. Paris. Crochard.

HUME, D. (1984). Tratado de la naturaleza humana, Bs. As.: Hyspamerica

MELOSSI, D. (2007). Estados fuertes y definidos de la conciencia colectiva (y la idea de una "responsabilidad compartida"), en Delito y Sociedad, UNL, 16, No 23, p.11-26

MOREL, B. (1857) Traité des dégénérescence de l'éspèce humaine. Paris. Baillére. 
RUGGIERO, V. (2005). Delitos de los débiles y de los poderosos, Bs. As.: Ad-HOC

SUTHERLAND, E. (1999). El delito de cuello blanco, Madrid: La Piqueta TARDE, G. (1922a). Filosofía penal, tomo I, Madrid: La España moderna TARDE, G. (1922b). Filosofía penal, tomo II, Madrid: La España moderna TARDE, G. (1922c). La criminalidad comparada, Madrid: La España moderna

TARDE, G. (1983). Las leyes sociales, Barcelona: Sopena

TARDE, G. (1986). La opinión y la multitud, Madrid: Taurus

TARDE, G. (2006). Monadología y sociología, Bs. As.: Cactus

TARDE, G. (2007). Criminalidad y salud social, en Delito y Sociedad, UNL Ed., 16, No 24, p. 121-132

TARDE, G. (2011). Sociología criminal y derecho penal, Bs. As.: Ad-Hoc

TARDE, G. (2011b). Creencias, deseos, sociedades, Bs. As.: Cactus

TONKONOFF, S. (2008). La sociología criminal de Gabriel Tarde, en Delito y Sociedad, UNL Ed., 16, N²6, p. 37-58

TONKONOFF, S. (2011). Lo social y sus paroxismos. El delito en la obra de Gabriel Tarde, en G. Tarde, Sociología criminal y derecho penal, Bs. As.: Ad-Hoc, pp. 9-36

VIRNO, P. (2003). Gramática de la multitud, Bs. As.: Colihue 